Old Dominion University

ODU Digital Commons

$1-2020$

Solutions for Fermi Questions, January 2020: Question 1: Car Flip; Question 2: A Mole of People

Larry Weinstein

Follow this and additional works at: https://digitalcommons.odu.edu/physics_fac_pubs

Part of the Physics Commons 


\section{Solutions for Fermi Questions, January 2020: Question 1: Car flip; Question 2: A mole of people}

Larry Weinstein

Citation: The Physics Teacher 58, A69 (2020); doi: 10.1119/1.5141955

View online: https://doi.org/10.1119/1.5141955

View Table of Contents: https://aapt.scitation.org/toc/pte/58/1

Published by the American Association of Physics Teachers

\section{ARTICLES YOU MAY BE INTERESTED IN}

Answer to January 2020 Figuring Physics

The Physics Teacher 58, A4 (2020); https://doi.org/10.1119/1.5141954

Question 1: Car flip; Question 2: A mole of people

The Physics Teacher 58, 69 (2020); https://doi.org/10.1119/1.5141981

Solution to the October, 2019 Challenge Up and Away...

The Physics Teacher 58, A70 (2020); https://doi.org/10.1119/1.5141956

SHOCK WAVE

The Physics Teacher 58, 4 (2020); https://doi.org/10.1119/1.5141957

Figuring Physics December 2019 Solution

The Physics Teacher 58, 71 (2020); https://doi.org/10.1119/1.5141983

January jiggle

The Physics Teacher 58, 70 (2020); https://doi.org/10.1119/1.5141982

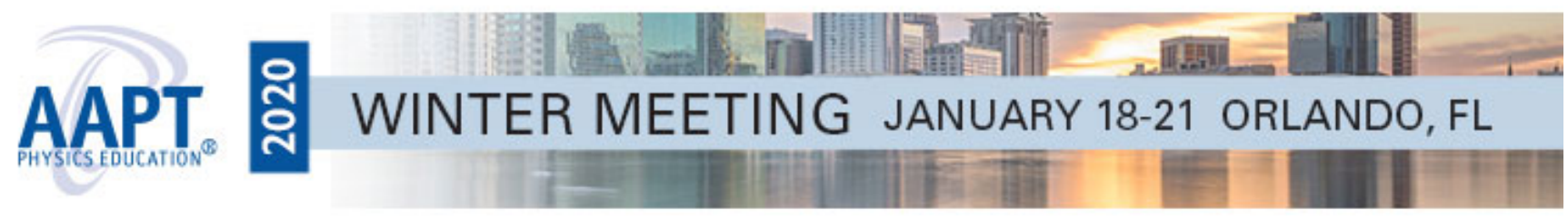




\section{Fermi Questions}

\section{Solutions for Fermi Questions, January 2020}

\section{Duestion 1: Car flip}

At what speed will a car flip over when it slides sideways into a curb? (Thanks to Reynier Cruz-Torres of MIT for suggesting the question.)

Answer: A speeding car failed to round a curve, slid sideways into a curb, and rolled over near my friend's apartment. What is the minimum speed for this to happen? First we need to look at what happens in the collision. When the car hits the curb (a low barrier) at a high enough speed, it starts to rotate around the top of the curb. Gravity exerts a torque that counters this rotation. The angular momentum of the car will depend on its initial speed, the height of the curb, and the height of the center-of-mass (CM) of the car. The torque will depend on the width of the car. The mass of the car is irrelevant.

Let's work out the physics and then estimate the relevant numbers. If we approximate the car as having all its mass located at its $\mathrm{CM}$, then its initial angular momentum relative to the top of the curb is

$$
L_{0}=m v\left(h_{\text {car }}-h_{\text {curb }}\right)=m v h \text {, }
$$

where $h$ is the height of the CM relative to the top of the curb. The initial rotational velocity will then be

$$
\omega_{0}=\frac{L}{I}=\frac{m v h}{m(w / 2)^{2}}=\frac{4 v h}{w^{2}}
$$

where $I$ is the moment of inertia and $w$ is the width of the car. The initial counter-acting torque will be

$$
T_{0}=m g(w / 2) \text {. }
$$

It will decrease to zero as the car rotates from horizontal to vertical.

At the minimum initial speed, the rotational inertia will decrease to almost zero when the car is vertical. This means that the average rotational speed will be

$$
\omega_{\mathrm{avg}}=\frac{2 v h}{w^{2}},
$$

(incorrectly assuming constant acceleration) and the time needed for the car to rotate from horizontal to vertical is

$$
t=\frac{\pi / 2}{\omega_{\text {avg }}}=\frac{\pi w^{2}}{4 v h}
$$

Thus the change in angular momentum due to the torque will be

$$
\Delta L=T_{\text {avg }} t=\frac{1}{2} T_{0} t=\frac{\pi m g w^{3}}{16 v h} .
$$

The car will roll over when $L_{0}>\Delta L$ or

$$
\begin{aligned}
& m v h>\frac{\pi m g w^{3}}{16 v h} \\
& v>\sqrt{\frac{\pi g w^{3}}{16 h^{2}}} .
\end{aligned}
$$

Thus, rollover depends only on the aspect ratio $w / \mathrm{h}$ and the width of the car (and the height of the curb).

Now we can estimate the height and the width of a typical sedan. My initial guess (oops, I mean estimate) for the width is $2 \mathrm{~m}$ (which gives a very convenient $w^{3} / 8=1 \mathrm{~m}$ ). Looking more closely, I know that my car seats three adults in back, if they're friendly. At a typical butt-width of 18 in each, plus 12 in for two doors, the width is actually 66 in or $165 \mathrm{~cm}$. Two meters is close enough. The height of the CM above the curb is a little more complicated. Most of the car mass is engine, transmission, and frame, so if we take half of the height of the hood (the top of the engine compartment), we should be OK. The hood is about at hip height, so I'll estimate that it's $1 \mathrm{~m}$, giving a center of mass height $h_{\mathrm{car}}=0.5 \mathrm{~m}$ and $h=h_{\text {car }}-h_{\text {curb }}=0.4 \mathrm{~m}$.

Let's see what we get:

$$
v_{\text {min }}=\sqrt{\frac{3\left(10 \mathrm{~m} / \mathrm{s}^{2}\right)(1 \mathrm{~m})^{3}}{2(0.4 \mathrm{~m})^{2}}} \approx 10 \mathrm{~m} / \mathrm{s},
$$

or about $20 \mathrm{mph}$. These are relatively low speeds.

If we're driving an SUV, then the center of mass will be higher. If it's a mere 8 inches higher, then $h=0.6 \mathrm{~m}$ and $v_{\min } \approx 7 \mathrm{~m} / \mathrm{s}$ or only $15 \mathrm{mph}$. Since

$$
v_{\text {min }} \propto \frac{1}{\left(h_{\text {car }}-h_{\text {curb }}\right)},
$$

the minimum velocity needed to make the car roll over decreases rapidly with vehicle height.

Be careful! Cars roll over at remarkably low speeds.

Copyright 2020, Lawrence Weinstein.

\section{Duestion 2: A mole of people}

How much is a mole of people? Consider mass, area, power, and food requirements. Make appropriately silly comparisons. (Thanks to Bryan Suits of Michigan Technical University for suggesting the problem.)

Answer: A mole is $6 \times 10^{23}$ thingies ("thingies" is a technical term). Let's look at the mass, area, power, and food requirements of a mole of people and compare that 
to the Earth. We'll consider mass and food first.

At a typical mass of $100 \mathrm{~kg}$ (in round numbers), a mole of people will have a mass of $6 \times 10^{25} \mathrm{~kg}$, which is 10 times the mass of the Earth. We each consume about $1 \mathrm{~kg}$ of food per day (more than 0.1 and less than $10 \mathrm{~kg}$ ) or about $400 \mathrm{~kg}$ per year. In an 80-year lifespan, we each consume $3 \times 10^{4} \mathrm{~kg}$ of food. Therefore, a mole of people consumes 40 Earth masses of food each year and 3000 Earth masses in a lifetime. That is $1 / 8$ of a Jupiter each year and 10 Jupiters for a full lifetime. We would eat the entire solar system much too quickly.

Now let's consider area. We each need $2 \mathrm{~m}^{2}$ to lie down and sleep, so we need a minimum of $10^{24} \mathrm{~m}^{2}$ for all of us. Since the surface area of the Earth is a mere

$$
A=4 \pi R^{2}=4 \pi\left(6.4 \times 10^{6} \mathrm{~m}\right)^{2}=5 \times 10^{14} \mathrm{~m}^{2},
$$

we'll need a lot more space. A Dyson sphere enclosing the Sun at a radius of $1 \mathrm{AU}$ will have an area of

$$
A=4 \pi R^{2}=4 \pi\left(1.5 \times 10^{11} \mathrm{~m}\right)^{2}=3 \times 10^{23} \mathrm{~m}^{2},
$$

which is too small by a factor of several. If we want to move around and not just lie down, then we will need many Dyson spheres.

Finally, let's consider power. Humans emit an average of $100 \mathrm{~W}$ of heat. A mole of us will emit $6 \times 10^{25} \mathrm{~W}$. This means that we will need to consume food containing that much energy. We can estimate the power output of the Sun from the solar flux at Earth radius, $S=10^{3} \mathrm{~W} / \mathrm{m}^{2}$ :

$$
P=4 \pi R^{2} S=\left(3 \times 10^{23} \mathrm{~m}^{2}\right)\left(10^{3} \mathrm{~W} / \mathrm{m}^{2}\right)=3 \times 10^{26} \mathrm{~W} \text {. }
$$

(the actual power output is $4 \times 10^{26} \mathrm{~W}$ so our estimate is very very close). Finally! The Sun can provide enough energy to power a mole of people, even if we don't have enough mass or area in the solar system to create or house all of us

Copyright 2020, Lawrence Weinstein. 